\title{
The Extended Corporate Identity Mix
}

\author{
Olutayo Otubanjo ${ }^{1}$ \\ ${ }^{1}$ Lagos Business School, Pan-African University, Lagos, Nigeria \\ Correspondence: Olutayo Otubanjo, Marketing, Lagos Business School, Pan-African University, Km 22 Lekki \\ Epe Expressway, Ajah, Lagos, Nigeria. E-mail: totubanjo@lbs.edu.ng
}

\author{
Received: September 12, 2012 Accepted: October 24, 2012 Online Published: January 14, 2013 \\ doi:10.5539/ijms.v5n1p59 URL: http://dx.doi.org/10.5539/ijms.v5n1p59
}

\begin{abstract}
Increasingly, industry practitioners now pursue corporate identity as a broad phenomenon spanning various business disciplines. However, very few works within corporate identity literature recognize this belief. As such it appears that literature on corporate identity, for the most part, has been narrowly conceived. The pursuit of corporate identity along the multidisciplinary perspective, especially among industry practitioners, encourages the author to develop what he terms an extended corporate identity mix that recognizes the broad nature of corporate identity. Specifically, the author suggests what he terms the extended corporate identity mix, which broadens the theory of corporate identity mix beyond the enclave of symbolism, behaviour communication, strategy, structure, and culture. Indeed, a major finding in this study is five new channels that contribute significantly to the expression of a firm's personality, comprising organization storytelling, core competence, visual style, and buyer value. The paper calls on academics to pursue corporate identity studies in such a way that the extended corporate identity mix that emerges from this paper is accommodated.
\end{abstract}

\section{Introduction}

Today, the concept of corporate identity is pursued, especially among industry practitioners, as a broad and multidisciplinary phenomenon. Unfortunately, the multidisciplinary nature of this discipline is only captured by a few authors within the corporate identity discipline (Birkigt and Stadler, 1986; Balmer, 2002). This paper adds to these works by offering 'an extended corporate identity mix' comprising organization storytelling, core competence, visual style, and buyer value. Additionally, the study demonstrates how these components serve as channels through which a firm's personality is conveyed to stakeholders. This paper has been divided into five major parts and this part constitutes the first. The paper continues in the second part with a brief review of the meaning of corporate identity mix. It discusses the elements of corporate identity mix in the third part and draws attention to some strengths and weaknesses of the concept. The fourth part presents five new elements of corporate identity mix. The paper ends with an analysis of the issues discussed in fifth part.

\section{The Meaning of Corporate Identity Mix}

The literature of corporate identity mix owes a lot of gratitude to Birkigt and Stadler's (1986) theory which narrowed the concept down to how a firm's personality is expressed through Symbolism, communication and behaviour. Following the publication of this influential work, many leading corporate identity authors belonging to the marketing mindset have attempted to clarify the meaning of corporate identity mix from the perspective of this philosophy. For instance, quoting Van Rekom et al. (1991), corporate identity mix has to do with "the self-presentation of an organization; it consists of the cues which an organization offers about itself via the behaviour, communication, and symbolism which are its forms of expression”. van Riel and Balmer (1997) followed Van Rekom et al. (1991), and concurred that corporate identity mix is "the way in which an organization's identity is revealed through behaviour (and) communications, as well as through symbolism to internal and external audiences". Similarly, Otubanjo and Cornelius (2008) avowed that corporate identity mix is a philosophy reflective of the channels through which a firm's personality is conveyed. Some of these channels include 'who/what you are', 'what you stand for' etc.

\section{Channels or Elements of Corporate Identity Mix}

A few studies have been put forward in literature to explicate the channels or elements of corporate identity. The author will in the paragraphs that follow discuss these in details: 
Birkigt and Stadler's (1986) theory of symbolism, communication and behaviour: symbolism refers to a set of visual identities that business organizations deploy either at corporate or product level to denote ownership and achieve differentiation. More importantly, it helps firms to express the nature of their personalities to stakeholders. Communication on the other hand represents the very many ways in which firms convey their entire personality to stakeholders. This may be through corporate advocacy advertising and corporate public relations. Behaviour denotes the ways that firms convey personalities through actions as well as through non-verbal behaviour, which can be planned or unplanned (Otubanjo et al, 2010).

Balmer and Soenen's (1998) theory of mind, soul, and voice: is to some extent grounded on Birkigt and Stadler's (1986) theory of symbolism, communication, and behaviour. For these authors, the 'mind' represents the vision, philosophy, strategy, performance, brand architecture, ownership, and history. The 'soul' denotes values, sub-cultures, employee affinities, and internal images. The 'voice' on the other hand reflects a firm's total corporate communication activities comprised of controlled and uncontrollable communication, indirect communication, symbolism, employee and corporate behaviour. These concepts provide channels through which a firm's personality is conveyed internally and externally.

Balmer's (2002) strategy, structure, communication, and culture perspective: this theory builds on Balmer and Soenen's (1998) work of the mind, mind soul and body. For Balmer (2002), strategy conscious decisions by senior management in the past which impact on the firm's personality today. These include management vision and philosophy, corporate strategy, service, product and financial performance, the corporate brand covenant and corporate architecture, and the nature of corporate ownership. Structure for Balmer (2002) reflects how a firm conducts its multiple relationships with subsidiaries, business units as well as alliance or franchise partners. Communication refers to the multi-faceted ways in which firms convey strategic intentions to stakeholders. Culture is a way of life in many organizations. According to Balmer (2002), culture is "that 'soft', subjective, albeit important, elements which are at the centre of an organisation's corporate identity".

\subsection{Benefits and Limitations of Corporate Identity Mix Literature}

Existing literature on corporate identity mix (Birkigt and Stadler, 1986; Balmer and Soenen, 1998; Balmer, 2002) contributes immensely towards a deepened understanding of the nature of corporate identity and other concepts of corporate personality. Contributions made by authors towards this concept have equally enhanced managerial understanding of the concept and how to better manage it. However, a number of elements, which equally serve as important channel through which the personality of firms are conveyed, are left out. The absence of these elements in literature motivates the need to offer a new set of channels which are of course consistently used by firms in the marketplace. These elements include organizational storytelling, core competence, corporate advertising and visual style.

\section{New Elements of the Corporate Identity Mix}

\subsection{Organizational Storytelling}

Stories are fundamental ways through which we understand the world (Bruner, 1990; Jameson, 1985; Tenkasi and Boland, 1993). Organizational storytelling is a comprehensive narrative history about the origin, strategic intention and other landmark achievements of an organization. Storytelling has been used in several cultures to convey stories from generation to generation about remarkable events in the lives of people in societies and it has been most useful in societies with little or no means of recording events (Johansson, 2004). Corroborating, Jabri and Pounder (2001) averred that storytelling serves to "express the richness and diversity of human experience and thus challenge simplistic analyses of management issues such as change that can result from adherence to narrow, mechanical models of human nature". It is a powerful tool used to evoke and heighten emotions. According to Adamson et al. (2006) "a good story always combines conflict, drama, suspense, plot twists, symbols, characters, triumph over odds, and usually a generous amount of humour - all to do two things: capture your imagination and make you feel. It draws you in, places you at its centre, connects to your emotions, and inserts its meaning into your memory". It is an integrative tool of corporate strategy. Stories create the experience of enhancing understanding of 'who and what' the organization is at corporate level. The use of stories has enhanced effective communication of organizational history to stakeholders (particularly the external ones) and has enabled organizations to capture stakeholders' imaginations and interest and provide the stimulus to pursue mutual understanding between organizations and stakeholders. Storytelling makes remarkable events in the history of organizations easier to remember and more believable. They are a powerful means of communicating organizational values, ideas, and norms to stakeholders. Stakeholders see themselves in stories and unconsciously relate it to their experience (Morgan and Dennehey, 1997). Stories entertain, evoke emotion, trigger visual memories, and strengthen recall about symbolic events in the lives of organizations and function as rhetoric for 
business organizations (Boje, 1995). As Brown (1990) argued, storytelling enhances the construction of various organizational activities and serves the purpose of explaining why specific decisions were taken in regard to certain business activities. Most importantly, stories are unique. They seek to differentiate the organization and position it as poles apart from others with similar business interests. They demonstrate that the institution is unlike any other (Martin, Feldman, Hutch and Sitkin, 1983).

Zemke (1990) put forward four important characteristics of organizational storytelling. First, the story must be concrete and talk about real people, describe real events and actions, be set in a time and place which the listener can recognize and with which he or she can identify. The story must be connected to the organization's philosophy and/or culture. Second, stories must be common knowledge in the organization. Stakeholders must not only know the story, but know that others know it as well and follow its guidance. Third, the story must be believed by the listeners. To have impact and make its point, a story must be believed to be true of the organization and fourth, the story must describe a social contract. (i.e. how things were done or not done in the organization) and must allow the listener to learn about organizational norms, rewards and punishments without trial-and-error experience. In the same vein, Brown (1990) advanced to literature 3 traits of organizational storytelling. He contends that organizational stories must first, reduce uncertainty for organizational stakeholders by providing reliable accounts of information about the organization and second, organizational stories must manage meaning by framing events within organizational values and expectations. Third and most important of all, organizational stories must identify why organizations and its members are special or unique.

Mogens Holten Larsen (2000) argued that what makes organizational storytelling different from all other corporate communication tools is not just its ability to construct the strategic intentions of the organization but its capacity in incorporating the core competencies, philosophical beliefs and values of that organization and that while providing deeper and strategic information about organizations, it is also a simple yet effective framework for guiding the activities of organizations and their members. Many organizations have employed the use of effective storytelling to create bond among employees on the one hand and also to build trust between the organization and employees on the other. Organizational storytelling is a very good vehicle for assuring the continued delivery of top quality goods and services, for peddling confidence and building corporate reputation among stakeholders. Mogens Holten Larsen (2000) averred that organizations that utilize legitimate reputation to explain its strategic intentions, through its contributions to society and commitment to add value, create a very strong opportunity of positioning itself no matter how competitive the market place may be. Many modern successful business organizations employed the use of storytelling not just to convey information about landmark events about their organization to internal and external stakeholders but most importantly to differentiate and distinguish themselves from others operating within their markets. Mogens Holten Larsen corroborates this view contending that the incorporation of the origin of organizations, strategic intentions and core competencies and all the words and visual images constructed in organizational stories provides a fundamental platform on which organizations differentiate themselves from others with similar business interests. Take the case of $3 \mathrm{M}$ as example. The organization differentiated itself strategically in the market place using storytelling to explain remarkable milestones in its history drawing from recollections of major participants in these milestones. The construction of such organizational stories helped $3 \mathrm{M}$ in understanding the many sources of its innovative culture together with the challenge to achieve buyer value (Porter, 1985) and differentiate itself from competitors. A full text of 3M 248 page organizational story has been published and is found at www. $3 \mathrm{~m} . c 0 \mathrm{~m} / \mathrm{about} 3 \mathrm{M}$ 


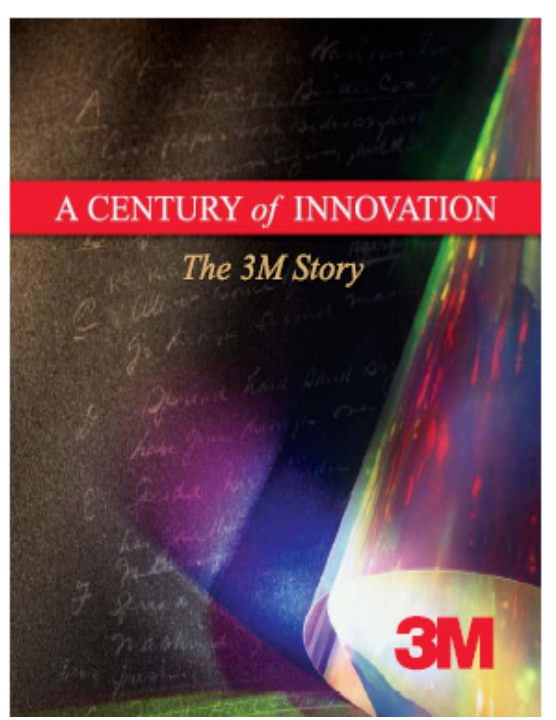

Figure 1.3M innovation story

Source: http://multimedia.mmm.com/mws/mediawebserver.dyn?FFFoMYRU\&i2Fsi2 Fsi2FFFw9Wq0M5nBu-

\subsection{Core Competencies}

The concept of core competencies, developed originally by Prahalad and Doz (1987), proposes that organizations should base their strategies around their core technical, competencies (Hussey, 1998) to transform, re-engineer business processes and achieve competitive advantage (Hamel and Prahalad, 1994). What, therefore, is a core competence? A core competence is a collection of various organizational skills and technologies (Hamel and Prahalad, 1996) representing the integration of various skills which differentiate organizations from competition. Core competence involves the harmonization and integration of various streams of technologies and the use of such technologies to deliver customer value (Prahalad and Hamel, 1990), Corroborating, Hamel and Henee (2000) added that the concept of core competence when applied adds disproportionately to customer value and enables the delivery highly valued benefits to customers. It is the collective learning relating to the coordination of diverse skills and the integration of multiple streams of technologies (Prahalad and Hamel, 1994). The integrated skills that lead to the emergence of core competencies are enhanced as they are shared among employees and do not diminish with use. Core competencies bind existing businesses and offer a guide to patterns of diversification and market entry. Hamel and Prahalad gave a summary of the meaning of core competence in their 1996 classic and best seller text: "A core competence is a bundle of skills and technologies that enables a company to provide a particular benefit to customers. At Sony that benefit is 'pocketability' and the core competence is miniaturization. At Federal Express, the benefit is on-time delivery and the core competence, at every high level, is logistics management. Logistics are also central to Wal-Mart's ability to provide customers with the benefits of choice, availability and value. At EDS, the customer benefit is seamless information flow and one of the contributing core competencies is systems integration. Motorola provides customers with benefits of 'untethered communications', which are based on Motorola's mastery of competencies in wireless communications".

Hamel and Heene (2000) theorised core competencies into three main categories, namely market access competencies, integrated related competencies and functionality related competencies. Market access competencies involve the development of skills that put organizations in close proximity with stakeholders. Integrated related competencies relates to quality management, cycle time management, just in time, inventory management and other skills that enable the delivery of products and services speedily with reliability and efficiency. Functionality based competencies however, encourage investment in products and services with unique functionality which invests the product with distinctive customer benefits. Functionally related competencies assume greater importance than the other two types of core competencies given the convergence of organizations around universally high standards of product and service integrity and the movement towards alliances, mergers and acquisitions and most importantly transformation and change. Rapid and dramatic changes in technology, government policy and business practices make the functionality based competence prone to change. Within a short period however, what constitutes a distinct functionality based competence to an organization becomes a generic competence common to all operators. This makes the transformation of competencies increasingly inevitable to organizations that seek market dominance and strategic competitive advantage. Core competencies, if 
identified, provide essential platforms for the rejuvenation, restoration and renewal of organizations towards market competitiveness. The process of transformation allows the appraisal of core competencies and its future prospect in terms of durability. The appraisal exercise is tantamount to the establishment of the core corporate identity (Hussey, 1998) which includes the strategic intent, unique combination of skills together with abilities and experience matched to opportunities that exploit strengths in identities and correct its weaknesses. The transformation of core competencies, which competitors find difficult to imitate (Hussey, 1998) therefore requires commitment of resources. A significant amount of funds must be committed to skill identification and development throughout the competence transformation exercise. While the commitment of large investment to the identification of core competencies is deeply appreciated, organizations must continuously sift out homogeneous competencies or generic identities (Olins, 1989; Olins, 1978) common to the industry and commit greater attention to the development of unique skills, which competing organizations find difficult to imitate. The transformation of core competencies presents another form of signification. By transforming the core competencies of organizations, especially the functionality based ones (Hamel and Heene, 2000); identity signals of transformation (founded on re-engineering, re-structuring) and renewal are communicated to stakeholders who, in turn, process and develop an image based on the transformative signals received.

\subsection{Corporate Advertising}

Modern advertising campaigns were originally developed to persuade and drive consumer purchase of a specific brand or service. However, with the arrival of modern business organizations and the jostle for leadership and market supremacy in various industries, another type of advertising called corporate or institutional adverting (Schumann et al. 1991) emerged to promote (Garbett, 1981) signify the differences between organizations and competition and most importantly build favourable corporate image about organizations in the minds of stakeholders. For this reason, organizations, particularly those in the financial services industry, have committed billions of pounds to corporate advertising campaigns. The committal of such huge investment into corporate advertising campaigns demonstrates the key role corporate advertising plays in the signification of organizational differences.

But what is corporate advertising? Aaker (1996) defined it as messages sponsored and communicated by organizations through the media to persuade consumers' perceptions of an organization and its products and their intentions to purchase the products. It is a 'catchall' term (Garbett, 1981) used to describe all forms of advertising that promote organizations as opposed to its products or services. The use of the word 'catchall' by Garbett suggests that over the years organizations have attempted to signify their differences through various forms of corporate advertising campaigns and most importantly there have been changes in the methodologies adopted by organizations in the signification of these differences.

After the Second World War, governments in western countries began to relax and dismantle controls on marketing activities. Restrictions on hire purchase of goods and services were lifted in 1954 in Britain, giving impetus and greater demand for goods and services in the marketplace. In addition, the media witnessed an unprecedented rise in the advertising of retail goods and groceries particularly between 1952 and 1954 (Nevett, 1982) further stimulating the demand for goods and services. Within a short period, fiercely competitive battles for market leadership rose and the desire to signify organizational goodwill and commitment to good public service as opposed to products, emerged. The aim of this new wave of communications was not only to signify organizational differences but to build favourable corporate image, achieve greater consumer patronage (Schumann et. al, 1991) and maintain market dominance. This type of advertising was called 'corporate' or 'institutional advertising'. In the following decades, there was, however, a change in the degree of use of corporate advertising as the 1960s and mid 1970s witnessed a lull in its use (Crane, 1980). By the late 1970s towards the late 1980s, however, the socioeconomic environment of business witnessed a massive change. Socioeconomic institutions including governments, religious bodies and even academic institutions suffered a huge loss in public trust and credibility. The private sector was not spared. Businesses, particularly publicly quoted organizations, declined in public confidence and credibility (Sethi, 1978) and there was the urgent need to counteract public scepticism of the social role of institutions and businesses through corporate led campaigns. There was a rising desire to take public opinion on controversial issues of social importance and engage and shape public discourse through various corporate communications campaigns (Sethi, 1978). Hence the use of corporate advocacy advertising emerged. Cutler and Muehling (1991) defined corporate advocacy as a special form of advertising in which organizations express their opinions on controversial societal issues in order to sway public sentiment and court good corporate image. It is a competitive tool created by organizations with the ultimate aim of shaping public opinion to create a business environment more favourable to their position. Since the late 1970s organizations have become increasingly active, adding their voices to social issues of national and even international importance. In fact many 
organizations have gone beyond the political realm adding voices to legislative issues (Lord, 2000) either through direct or indirect lobbying (Armey, 1996; Kuntz, 1995). By adding their voice to issues of social and environmental concern, organizations shape public policies, reduce uncertainties in the business environment, reduce existing threats and create trust among stakeholders. By adding voice and signifying support to prevailing social issues, many organizations have (in the process) courted public support for their businesses, achieved competitive advantage (Lord, 2000), differentiated themselves from competition and secured impeccable corporate image.

Although the use of corporate advocacy advertising continues to dominate the media, an addition to the discipline of corporate advertising called 'market preparation' advertising, which gives greater emphasis to corporate identity emerged in the early 1990s. Three multidisciplinary factors explain the reasons why many organizations turned to the use of market preparatory advertisements. First are corporate marketing led factors of shortening product life cycles, the desire among corporations for differentiation, merger and diversification/consolidation activities, and high rates of media inflation. Other factors include the redefinition of businesses from a marketing perspective, increasing recognition of the value of integrated marketing communications, finer approaches to segmentation, rising incidence of crisis situations among corporations (Marwick and Fill, 1997), a rise in product innovation and reorientation of corporations towards customer service (Schmidt, 1995). Second are socio-economic factors of the unification of Europe, challenges of economic recession, value change and related increase in environmental awareness, opportunities and challenges of the European market(Schmidt, 1995), and privatisation and divestment of government stocks (Wilkinson and Balmer, 1996). Third are business and strategy-induced factors of globalisation of markets and production, stiffer competition, rising cost of business operations and crises in many areas of industry. Others include increased desire for re-engineering and many other factors, which place severe challenges on corporations' national and international competition more than ever before (Schmidt, 1995). The main aim of this sort of advertisement is to convey information relating to reputation derived from its history, core competencies and contributions of the organization to stakeholders. More importantly, it is designed to signify organizational differences and court a favourable image for its users.

\subsection{Visual Style}

The use of strong visual identity styles first attracted the attention of business organizations in 1908 when Allgemeine Electrizitats Gesellschaft (AEG) a German electrical appliance manufacturing organization designed a visual style (i.e logos/signage, uniforms, business cards, letterheads/stationery designs, vehicle liveries, company reports, promotional materials and internal memos etc.) to unify its array of product lines, integrate its operations into a monolithic identity, build a powerful corporate identity, differentiate itself from emerging competitors and build a stable but conservative visual image. The use of conservative visual styles continued unabated until the late 1950s and over this period a series of conservative visual identity styles were designed for Studebaker cars and Greyhound buses (Carls, 1989).

Between the late 1950s and mid 1970s, however, the effects of competition began to bite heavily and the need to exhibit very strong unified identity globally using word-marks emerged paving the way for the relegation of conservative visual styles (Carls, 1989). The word-mark style of design allows the full spelling of the name and cements corporate names in the minds of stakeholders. Many organizations, particularly those in United States, Britain and Japan constructed their visual corporate identities drawing heavily from the Swiss Modernist School of Design, which advocated the use of word-marks using Helvetica typeface/letters, grey or blue colors and clinical images incorporating the organization's brand name into a uniquely styled type font treatment to construct desired images in the minds of stakeholders. Fonts like script font were commonly used to signify formality or in fact corporate re-structuring. Bold fonts like IBM proclaimed strength and power and slanted thick type fonts like FedEx conveyed motion or movement or speed. Hand-drawn letters, characters or symbols were designed to intrigue target audiences and arrest interest. Besides the intentions of organizations, the main objective of the word-mark is to construct a formal identity of speed and dynamism, symbolize presence in the marketplace, achieve maximum visual effect, cement brand name in the minds of stakeholders, differentiate its users from competitors and achieve a strong corporate image. These new approaches to visual style took on a more solid, well grounded and well balanced appearance to project and signify desired organizational messages and differentiate the organization (Carls, 1989). Within the same period, many small, medium-sized, young enterprising organizations emerged as powerful competitors challenging bigger ones with a new sense of corporate identity accompanied by very strong competing corporate messages that made them stand out in the market place. These new organizations adopted idiosyncratic artistic flair to corporate identity design challenging the cold rationalism of the older conservative generation (Carl, 1989). The Apple user-friendly, postmodern identity was designed to 
convey the notion of high technology to challenge IBM's new corporate identity, which conveyed a message of speed and dynamism.

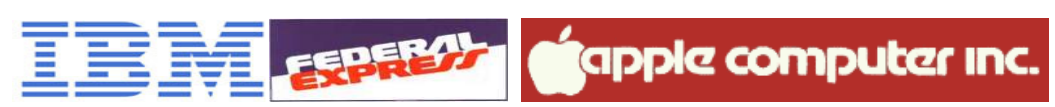

Figure 2. Word-marks

Source: http://www-03.ibm.com/ibm/history/exhibits/logo/logo_8.html

Source: http://en.wikipedia.org/wiki/FedEx http://www.fedex.com/gb/

Source: http://en.wikipedia.org/wiki/Apple_fonts

Again during this period, a new wave of identity construction emerged and organizations began to adopt the use of glyphs to represent themselves graphically. They are less direct than straight text, leaving room for broader interpretation of what the organization represents. They are iconic, compelling and uncomplicated. They are used to convey literal or abstract representation of organizations. During this period, however, glyphs were not generally used for logos, but as communication devices, such as the 1972 Olympic event icon (a crown of ray of lights) representing the spirit of the Munich Olympic Games - light, freshness and generosity. Glyphs provided organizations with the most impact and enhanced the creation of a sophisticated, intellectual corporate identity for those that adopted it. Shell and the Munich Olympic glyphs (below) were designed by Raymond Loewy in 1971 and Otl Aicher in the late 1960s respectively to give distinct identities to its promoters.

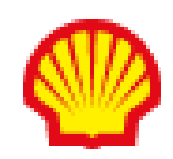

Figure 3. Glyphs

Source: http://www.shell.com

Source: http://www.olympic.org

The use of humanism and populism in corporate designs and logos also emerged over this period. Organizations like Prudential Insurance Plc (UK) exploited the rich complexities of their cultural societies embracing logos with the feature of human logo designs that stakeholders, particularly consumers, could identify with.

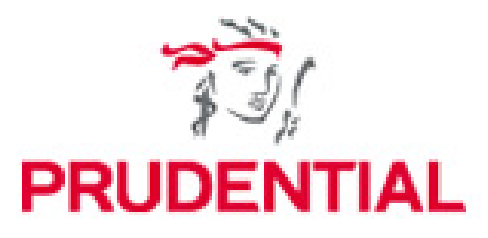

Figure 4. Prudential's human face identity

Source: http://www.prudential.co.uk/prudential-plc/splash/

Beginning in the 1980s, organizations began to express corporate visual identities either through passive or active visual identity programs. Under passive corporate identity programs, firms developed single and uniform marks for every application. The same logo accompanied by the same color and typestyle appears on all business cards, stationery designs, vehicle liveries, company reports, promotional materials and internal memos.

Many large organizations like AT\&T lost confidence in their old globe symbol styled logo which had all the hallmarks of standardized passive corporate identity style of approach and embraced the flexible visual approach offered in active identity programs that allowed the flexible construction of their identity. The active identity 
program allowed organizations to maintain greater flexibility and less rigidity in their visual applications. Many organizations that adopted this approach expressed their corporate identity in a series of compatible, but non uniform ways. It allowed organizations to change and evolve without the need to rid its entire visual identity as change evolved over time. Increasingly, the use of active identity programs rose among very big organizations, presenting themselves with more diverse visual identities (Carl, 1989). As much as the active approach allowed for greater flexibility, it also came with several challenges, which managers found difficult to implement. For instance the AT\& T active identity program came with as many as 24 versions and a complex set of rules to ensure proper usage. Despite these rules and intense monitoring, confusion led to frequent and costly misuse of the active programme. This became a real problem for AT\&T managers to deal with and the problem is reflected in the publication of articles discussing the use of the logo with employees. (See http://www.bellsystemmemorial.com/pdf/att_globe.pdf accessed, January 2006)

Logo of AT\&T as constructed in a newspaper advertisement in 1984.

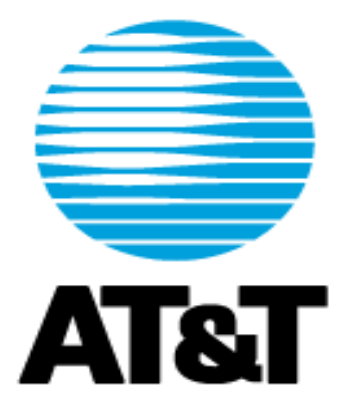

Figure 5. AT\&T's iconic visual identity

Source: http://www.bellsystemmemorial.com/bell_logos.html
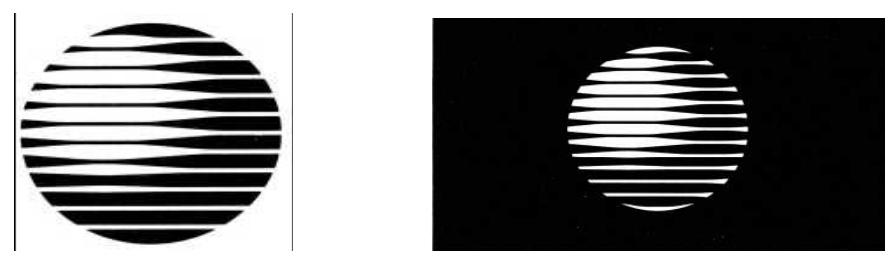

Figure 6. AT \&T's visual identity

Source: http://www.bellsystemmemorial.com/pdf/att_globe.pdf

\subsection{Buyer Value}

The differentiation of organizations through products and services is achieved when products or services offered for sale are deemed to add value to customers. However, the extent to which organizations can differentiate themselves through their products remains an important issue. Product differentiation allows firm to command premium price, sell more products at specific prices, and maintain customer loyalty even during market turbulence.

Since the 1940's, customer value was predominantly equated to price. Several attempts were made during these periods to reduce product pricing to achieve differentiation from competitors. Given the rising level of competition and lower market entry barriers in many industries, the trend began to change. Right from the 1970's value adding became a more complex issue and organizations responded with equally more sophisticated methods. Besides offering products at reduced prices, emphasis was laid on shopping convenience and timing. Many organizations were positioned differently through corporate communications conveying messages relating to the benefits of convenience of speedy services.

The economic recession of the 1980's fuelled the emergence of a new set of conservative and cautious spending consumers replacing the hedonistic, shop-'til -you-drop philosophy that blossomed earlier in the decade (Levere, 1992). The majority of organizations that attempted (in the years that followed) to differentiate themselves by 
providing superior customer value to customers did so narrowly. The provision of higher buyer value was approached by tinkering with the physical aspects of organizational products or marketing practices(Porter, 1985) or at best bringing prices down to achieve greater sales volume. During that period, many business organizations invested huge sums of money, time and effort in the visual designs on their products to distinguish them from those belonging to competing organizations. Organizational products and services were converted into branded portfolios through various marketing communications efforts and many business organizations competed by building and maintaining product or service quality at reduced priced, rationalizing their product portfolios and improving supply-chain management (Maklan and Knox, 1997). Although, these efforts yielded returns, they were, however, short lived.

Various environmental trends including the explosion of the mass media in the early 1990s cum other integrated marketing communication practices (Belch and Belch, 1995) together with rapid technological advancements enhanced greater customer awareness and customers began to demand greater value for money more than ever before. Consequently, many business organizations that could not meet 'customer value' demand suffered huge loss in market share as customers refused to accede to premium products offered for sale by many industry leaders (Maklan and Knox, 1997). As a result, business organizations began to take a second but critical look at their value chain practices. Today, businesses now search for new opportunities to achieve, retain, upgrade and leverage competitive advantages (Yonggui Wang et al. 2004) and differentiate products effectively through buyer value. According to Levere (1992) "many organizations are responding to this increased demand for value by adopting innovative marketing strategies, or by using a previously established value orientation to win new customers while maintaining their traditional customer base".

\section{Conclusion}

This paper makes an attempt to broaden our academic and managerial understanding of the concept of corporate identity by extending the concepts of corporate identity mix. Previously, existing works failed to recognize the role of these five new emerging phenomena in conveying a firm's personality to stakeholders. Specifically, previous works (Birkigt and Stadler, 1986; Balmer and Soenen, 1998; Balmer, 2002) champion the positioning of symbolism, communication, behaviour, mind, soul, and voice, strategy, structure, and culture as dominant elements of corporate identity mix. However, contributions emerging from this study indicate that the elements of corporate identity mix are not limited to what is obtainable in academic literature. This study provides evidence to suggest that the concepts of organization storytelling, core competencies, corporate advertising, visual style and buyer value, in addition to existing elements; equally serve as channels through which a firm's personality can be conveyed to stakeholders. These contributions are unique given that these new concepts are yet to appear in literature as channels or elements of corporate identity mix.

\section{References}

Aaker, D. A. (1996). Building strong brands. Free Press, New York.

Adamson, G., Joe, P., Tom, V. S., \& Jodi, K. (2006). How storytelling can drive strategic change. Strategy and Leadership, 34(1), 36-41. http://dx.doi.org/10.1108/10878570610637876

Armey, D. (1996). How taxes corrupt. Wall Street Journal, p.A20.

Balmer, J. M. T. (2002). Mixed-up over identities, working paper No 02/32. Bradford School of Management, University of Bradford.

Balmer, J., \& Soenen, G. (1998). A new approach to corporate identity management. International Centre for Corporate Identity Studies, Working Paper, 1998/5.

Belch, G., \& Belch, M. (1995). Introduction to advertising and promotion. Irwin, Chicago.

Birkigt, K., \& Stadler, M. M. (1986). Corporate identity, grundlagen, funktionen, fallspielen. Verlag Moderne Industrie, Landsberg an Lech.

Boje, D. M. (1995). Stories of the Storytelling Organization: A Postmodern Analysis of Disney as Tamara-land. Academy of Management Journal, 38, 997-1035. http://dx.doi.org/10.2307/256618

Brown, M. H. (1990). Defining stories in organization: Characteristics and functions. Communication Yearbook, 13, 162-190.

Bruner, J. S. (1990). Acts of Meaning. Cambridge, MA: Harvard University Press.

Carls, K. (1989). Corporate coats of arms. Harvard Business Review, 67, May/June, 135-139. 
Crane, F. G. (1990). The need for corporate advertising in the financial services industry: a case study illustration. Journal of Services Marketing, 4(2), 31-37. http://dx.doi.org/10.1108/EUM0000000002509

Cutler, B. D., \& Muehling, D. D. (1991). Another Look at Advocacy Advertising and the Boundaries of Commercial Speech. Journal of Advertising, 20(4), 49.

Garbett, T. F. (1983). Researching Corporate Advertising. Journal of Advertising Research, 23(February/March), 33-37.

Hamel, G., \& Heene, A. (2000). The Concept of Core Competence. Competence Based Competition. John Wiley and Sons, Chichester

Hamel, G., \& Prahalad, C. K. (1996). Competing for the Future. Harvard Business Press.

Hussey, D. (1998). Strategic management: from theory to implementation. Butterwood and Heinemann, London.

Jabri, M., \& Pounder, J. S. (2001). The Management of Change: A Narrative Perspective on Management $\begin{array}{lllll}\text { Development. Journal of Management Development, } & \text { 20, }\end{array}$ http://dx.doi.org/10.1108/02621710110401400

Jameson, F. (1985). The Political Unconsciousness: Narrative as a Socially Symbolic Act. London: Methuen.

Johansson, A. W. (2004). Consulting As A Story-Making. The Journal of Management Development, 23(3/4), 339. http://dx.doi.org/10.1108/02621710410529794

Kuntz, R. (1995). Attempt to Toughen Lobbyist Disclosure Law Leaves Huge Loophole For “grass-roots" Money. Wall Street Journal, p. A16.

Levere, J. (1992). The value of added value. Incentive, 166(5), 18-21.

Lord, M. D. (2000). Corporate Political Strategy and Legislative Decision Making. Business and Society, 39(1), 76-94. http://dx.doi.org/10.1177/000765030003900106

Maklan, S., \& Knox, S. (1997). Reinventing the Brand: Bridging the Gap between Customers and Brand Value. Journal of Product and Brand Management, 6(2), 119. http://dx.doi.org/10.1108/10610429710175655

Martin, J., Feldman, M. S., Hatch, M. J., \& Sitkin, S. B. (1993). The Uniqueness Paradox in Organizational Stories. Administrative Science Quarterly, 28, 438-53. http://dx.doi.org/10.2307/2392251

Marwick, N., \& Fill, C. (1997). Towards a framework for managing corporate identity. European Journal of Marketing, 31(5/6), 396-409. http://dx.doi.org/10.1108/eb060639

Mogens, H. L. (2000). How brands are taking over the corporation. Oxford University Press.

Morgan, S., \& Dennehy, R. F. (1997). The Power of Organizational Storytelling: A Management Development $\begin{array}{llll}\text { Perspective. The Journal of Management Development, } 16(7), & 494 .\end{array}$ http://dx.doi.org/10.1108/02621719710169585

Nevett, T. R. (1982). Advertising In Britain: A History. Heinemann, London.

Olins, W. (1978). The corporate personality: an inquiry into the nature of corporate identity. Design Council, London.

Olins, W. (1989). Corporate identity: making strategy visible through design. Thames and Hudson, London.

Otubanjo, B. O., Amujo, O. C., \& Cornelius, N. (2010). The informal corporate identity communication process. Corporate Reputation Review, 13(19). http://dx.doi.org/10.1057/crr.2010.18

Otubanjo, B. O., Melewar, T. C., \& Cornlelius, N. (2008). Stability and change: how firms construct the meaning of corporate identity, 1970-2005. Retrieved from http://papers.ssrn.com/sol3/papers.cfm?abstract_id=1299640

Porter, M. E. (1985). Competitive Advantage: Creating and Sustaining Superior Performance. London, Collier McMillan.

Prahalad, C. K., \& Doz, Y. L. (1987). The multinational mission. The Free Press, NY.

Prahalad, C. K., \& Hamel, G. (1994a). Strategy as a field of study: Why search for a new paradigm? Strategic Management Journal, Summer Special Issue, 15, 5-16.

Prahalad, C. K., \& Hamel, G. (1994b). The core competence and the corporation. Harvard Business Review, May - June, 71-91.

Schmidt, K. (1995). The quest for identity. Cassell, London. 
Schuman, D. W., Jan, M. H., \& Susan, W. (1991). Corporate Advertising in America: A Review of Published Studies on Use, sMeasurement, and Effectiveness. Journal of Advertising, 20(3), 35-56.

Sethi, S. P. (1978). Advocacy Advertising:-The American Experience. California Management Review, Fall, 55. http://dx.doi.org/10.2307/41165295

Tenkasi, R. V., \& Boland, R. J. (1993). Locating Meaning Making in Organizational Learning: The Narrative Basis of Cognition. In R. W. Woodman \& W. A. Pasmore (Eds.), Research in Organizational Change and Development (Vol. 7). Greenwich, CT: JAI Press.

van Rekom, J., van Riel, C. B. M., \& Wierenga, B. (1991). Corporate identity. Van vaag concept naar hard feitenmateriaal. Working Paper, Corporate Communication Centre, Erasmus University Rotterdam.

van Riel, C. B. M., \& Balmer, J. M. T. (1997). Corporate identity: the concept, its measurement and management. European Journal of Marketing, 31(5), 340-355. http://dx.doi.org/10.1108/03090569710167574

Wilkinson, A., \& Balmer, J. M. T. (1996). Corporate and generic identities: lessons from the Co-operative Bank. International Journal of Bank Marketing, 14(4), 22-35. http://dx.doi.org/10.1108/02652329610119292

Yonggui, W., \& Hing, P. L., \& Yongheng, Y. (2004). An Integrated Framework for Service Quality, Customer Value, Satisfaction: Evidence from China's Telecommunication Industry. Information Systems Frontiers, 6(4), 325-340. http://dx.doi.org/10.1023/B:ISFI.0000046375.72726.67

Zemke, R. (1990). Storytelling: back to basics. Training Magazine, 27(3). 